\title{
Study impact toughness on polyester matrix composite fiberglass reinforced Musa acuminata stem fibers as raw material of rear bumper vehicle
}

\author{
Sujita Darmo Darmo ${ }^{1,{ }^{*}}$ and Rudy Sutanto Sutanto ${ }^{2}$ \\ Department of Mechanical Engineering, Faculty Engineering, Mataram University, Majapahit Street 62, Mataram 83125, \\ Indonesia.
}

Publication history: Received on 06 December 2020; revised on 14 December 2020; accepted on 16 December 2020

Article DOI: https://doi.org/10.30574/gjeta.2020.5.3.0112

\begin{abstract}
The use of natural fibers as composite reinforcement has various advantages, including as substitute for artificial fiber, low price, able to reduce sound, environmentally friendly, has low density, good fit and ability to absorb impact energy, making it possible to use it as a vehicle accessory such as a rear bumper vehicle. This study aims to investigate the impact toughness performance of the fiberglass matrix composite polyester (FMCP) reinforced fiber Musa acuminata stem fiber (MASF), with a volume fraction of 5\%,10\%,15\%, 20\% and 25\%. Polyester matrix type 157 is used BQTN and G3253T, MEKPO catalyst. The impact toughness test was carried out by using the charpy method impact test instrument, observing the microstructure of the occurrence of fracture by using scanning electron microscope (SEM). The composite impact test specimen was 12.7 thick mm refers to the ASTM D 256 standard, produced by the hand layup method. The most optimal volume fraction impact test at a volume fraction of 20\% MASF: 80\% Matrix, with an impact energy of $14.47 \mathrm{~J}$, impact toughness $0.094 \mathrm{~J} / \mathrm{mm}^{2}$. The results showed that the addition of MASF increased the impact toughness of the composite by $14.69 \%$ compared to composites $0.0122 \mathrm{~J} / \mathrm{mm}^{2}$. Based on SEM observations, it can be seen that the $20 \%$ MASF volume fraction of the bonds between the matrix and the fibers are perfectly integrated. The results showed that the addition of MASF increased the impact toughness of the composite by $14.69 \%$ compared to composites $0.0122 \mathrm{~J} / \mathrm{mm} 2$. However, if a volume fraction ratio above $20 \%$ MASF is used, the impact toughness is decreased.
\end{abstract}

Keywords: Polyester Matrix Composites Fiberglass; Musa acuminata Stem Fiber; Impact Toughness; Rear Bumper

\section{Introduction}

The polyester matrix composite reinforced natural fibers present a great potential application in the automobile industry, especially in the bumper of automobiles, bus and trucks. The future perspective for the use of natural fibers is very good also in other areas. For instance, the textile industry is now with expansion international market. In the last years, use of natural fibers as, coconut, sisal, rami, sugar-cane pulp, jute and pineapple as reinforcement in polymeric material had an accelerated growth. They are source of renewable natural resource [2,11]. The rear bumper is one part of the vehicle that has a very important role, apart from being aerodynamic and aesthetically pleasing to attract consumers, the bumper also functions as a collision damper from the rear that occurs in the vehicle. Therefore, the material used as the rear bumper often gets damaged during a collision, so it requires a material that has good impact toughness, is light, ductile and corrosion resistant. Natural fibers present low cost, are biodegradable, recycled, no poisonous and can be incinerated. They are being used as reinforcement in polymeric and substitute synthetic fibers partially as asbestos, Kevlar, boron, carbon, nylon and glass. In spite of these good mechanical characteristics, they present a high cost, are abrasive to the processing equipment's, possess high density, generate products with very high recycling cost, besides some of those fibers commit human health [1,9].

\footnotetext{
${ }^{*}$ Corresponding author: Sujita Darmo

Department of Mechanical Engineering, Faculty Engineering, Mataram University, Majapahit Street 62, Mataram 83125, Indonesia. 
Matrices have as main purpose to transfer the stresses imposed on the composite material to the fibers, as well to serve as a support and protection of the fibers. Generally, composite matrices of thermosetting resins are used because they have great mechanical properties and dimensional stability. They are also resistant to chemical attack and have high thermal resistance [10]. According to Bento [3] the matrix has three main functions which are: to protect the surface of fibers from damage by abrasion that would lead to fracture, adhere in the surface in order to transfer the force has applied to the same fiber, to separate the fibers each other in order to improve the resistance of propagation of transverse cracks to other fibers.

The importance of this mechanical analysis is based on determining the strength of the structural design to provide confidence in the safety of use. The description above shows that impact strength is important to assess. Factors that greatly influence the increase the strength of natural fiber composites is a factor of fiber volume fraction or fiber content. In principle, all fiber nature has a fairly high strength (above $100 \mathrm{MPa}$ ). The low-strength composite behavior is usually caused by uncontrolled fiber reinforcing content.

The research on polyester pineapple fiber composites shows that treatment of pineapple fiber by immersion in alkaline solution $(\mathrm{NaOH}) 10 \%, 20 \%, 30 \%$ and $40 \%$ for 2 hours have a better tensile strength than the tensile strength at the same treatment for 4 hours $[5,6]$. Treatment of pineapple fiber by soaking in $10 \%, 20 \%, 30 \%$ ethanol solution and $40 \%$ for 2 hours is also better than treatment for 4 hours. Pineapple fiber treatment with soaking alkaline solution (NaOH) and ethanol (C2H5OH) 10\%, 20\%, 30\% and 40\% for 2 hours and 4 hours against the best compatibility (interfacial shear stress) of pineapple fibers on fibers that have been treated for 4 hours [10].

The addition of maleic anhydride was shown to improve properties of the bio composite. Tensile strength of the PBSMA and PLA-MA treated bio composite as well as the bio composite SEBS-MA and Mapp treatments are increasing [3]. This is evidenced by the fault section that occurs at SEM photo-micro results. The modulus of elasticity (E) also increased compared to the bio composite who do not experience treatment. This proves that with this treatment the interfacial bond increasing, which will have an impact on increasing the mechanical properties and thermal properties of the bio composite.

The mechanical properties of hybrid composites banana / kenaf fiber with a polyester matrix using Sodium Laulryl Sulfate (SLS) treatment. Research result showed that SLS treatment can improve the mechanical properties of hybrid composites compared to alkaline treatment $[4,7,8]$. The SLS treatment has improved the mechanical properties, tensile, bending and impact strength of the hybrid. Random fiber composites and woven fibers were better than those with alkaline treatment.

This study aims to determine the mechanical properties (tensile and impact) of woven Musa acuminata stem fiber reinforced composites with a polyester matrix, for the feasibility of these composites as an alternative solution to the replacement material for vehicle bumpers categorized as Multi-Purpose Vehicle (MPV) which in its application is closely related to safety usage especially in the automotive sector.

\section{Material and methods}

\subsection{Materials}

The research materials are Musa acuminata stem fiber, Polyester matrix type 157 BQTN and G3253T, MEKPO catalyst. The equipment used are charpy impact test equipment, digital scales, macro photos and composite fabrication equipment.
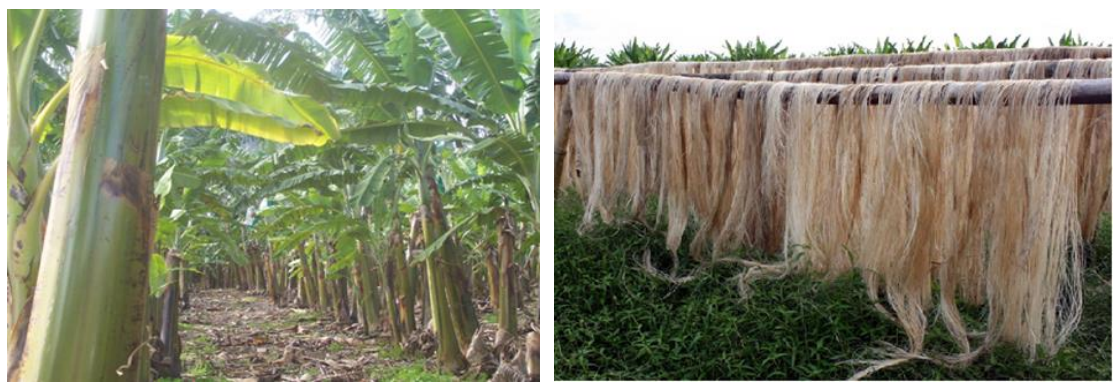

Figure 1 a. Musa acuminata stem. b. Musa acuminata stem fibers 


\subsection{Methods}

Composite panels are made by using the press mold method. Variable this study is the volume fraction of Musa acuminata stem fibers by $5 \%, 10 \%, 15 \%$, and $20 \%$. The composite impact test specimen was 12.7 thick mm refers to the ASTM D 256 standard, as shown in Figure 2. The fracture section of the test specimen is subjected to a macro photo to identify the pattern failure.

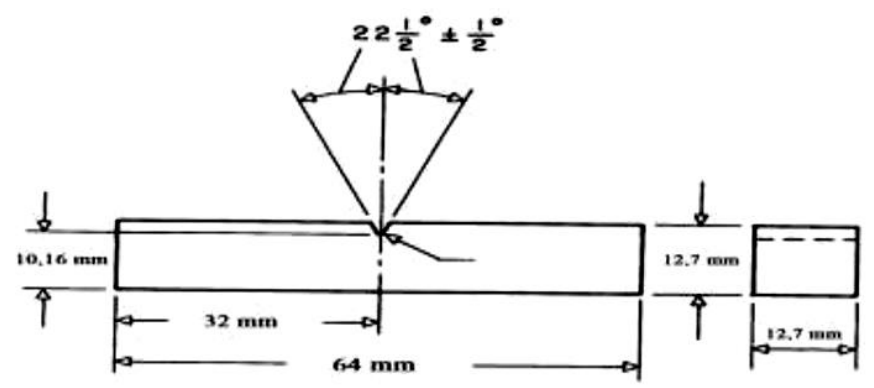

Figure 2 Impact test specimen ASTM D 256 standard

\section{Results and discussion}

\subsection{The impact toughness analysis}

The results of the impact test are in the form of impact strength value and absorption energy curve versus volume fraction are shown respectively in Figure 3 and 4.

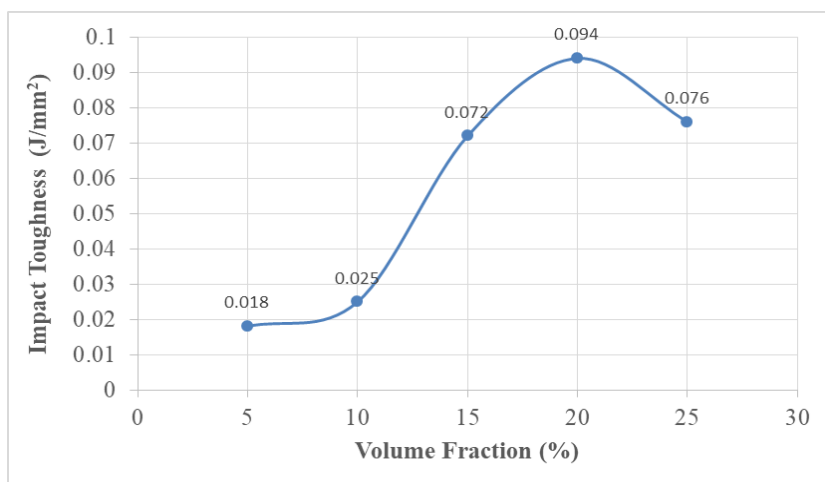

Figure 3 Impact touhgness for specimen

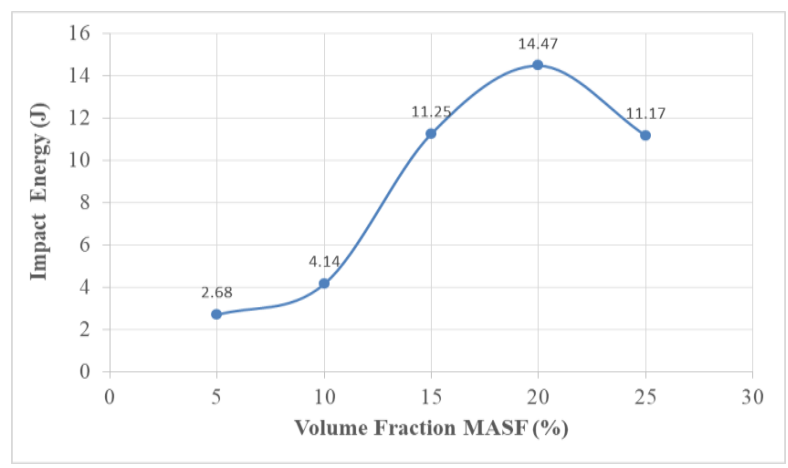

Figure 4 Impact energy for specimen 
Based on the analysis of the data, the most optimum impact toughness occurs in fiberglass composites with a volume fraction of $20 \%$ MASF, shown in Figure 3. When viewed in terms of impact strength, the addition of volume fraction of Musa acuminata stem fiber increases the fiberglass composite impact toughness. The MASF reinforced fiberglass composite impact strength has the highest at $20 \%$ volume fraction. Thus, ductility of material is arguably better, allowing for raw material of rear bumper vehicle. Impact touhgness, which is the strength of the highest average value found in the $20 \%$ volume fraction of MASF about $0.094 \mathrm{~J} / \mathrm{mm} 2$ and the lowest average value is found in the $5 \%$ volume fraction of MASF about $0,018 \mathrm{~J} / \mathrm{mm} 2$

Furthermore Musa acuminata stem fiber (MASF) reinforced fiberglass composite be able to increase the absorption of higher impact energy with addition volume fraction from $5 \%$ to $20 \%$. However, at a volume fraction of Musa acuminata stem fiber $25 \%$ lower energy impact. Increase in volume fraction causes the impact energy higher. The Impact energy data taken is the impact strength of the five volume fractions of MASF. The highest average impact energy strength in the $20 \%$ volume fraction of MASF, which is 14,47 Joule and the lowest average value is in the $5 \%$ volume fraction of MASF, about 2,68 Joule. The increase in energy impact along with the addition of fiber or the volume fraction of MASF is increasing, and this is due to an increase in binding power between matrix polyester and fiber which is very good. When given a load from the outside the first to break is the matrix, then followed by the fiber itself and the fiber does not break at once but there are still some fibers that are still intact so that the composite Impact energy has a significant increase, at a fiber volume fraction of MASF 5 to 20\%,25\% down again, the dominance of MASF whose strength is lower than fiberglass.

\subsection{Analysis of specimen failure}

Analysis of the Scanning Electron Microscope (SEM) was carried out after testing the impact strength to determine the bond structure between the fibers (fiberglass - MASF) as reinforcement with polyester as a binder (matrix). From Figure $5 \mathrm{~d}$, the volume fraction with the $20 \%$ volume fraction of MASF, matrix $80 \%$ mixture shows that the fibers adhere well, it can be seen that after damage to the composite surface after the impact test, there is still a little visible fibers that are pulled out and cause pores, indicating the strength of the matrix bond is getting better. From Figure 5a. Filler comparison of 5\% volume fraction of MASF, 95\% matrix shows the strength of the matrix bond is decreasing and you can see the fibers are pulled out, and there are many pores, this is because there is no good bond between the fiber and the matrix in the composite material.

Based on the fracture macro photo Figure 5 shows the fracture at the bottom of all specimens test. This is because during the impact test, the upper part of the specimen was subjected to a compressive load while the lower part was subjected to a tensile load resulting in a fracture at the bottom as shown in Figure 5. From Figure 4, it can be seen that the specimen with a fiber length of $5 \mathrm{~cm}$ has a fracture smaller fracture when compared to specimens with a fiber length of $2 \mathrm{~cm}$. This matter because the longer the fiber, the greater the reinforcement given to it matrix so that the matrix fiber bonds are getting stronger. The fracture form is dominated by brittle fracture.
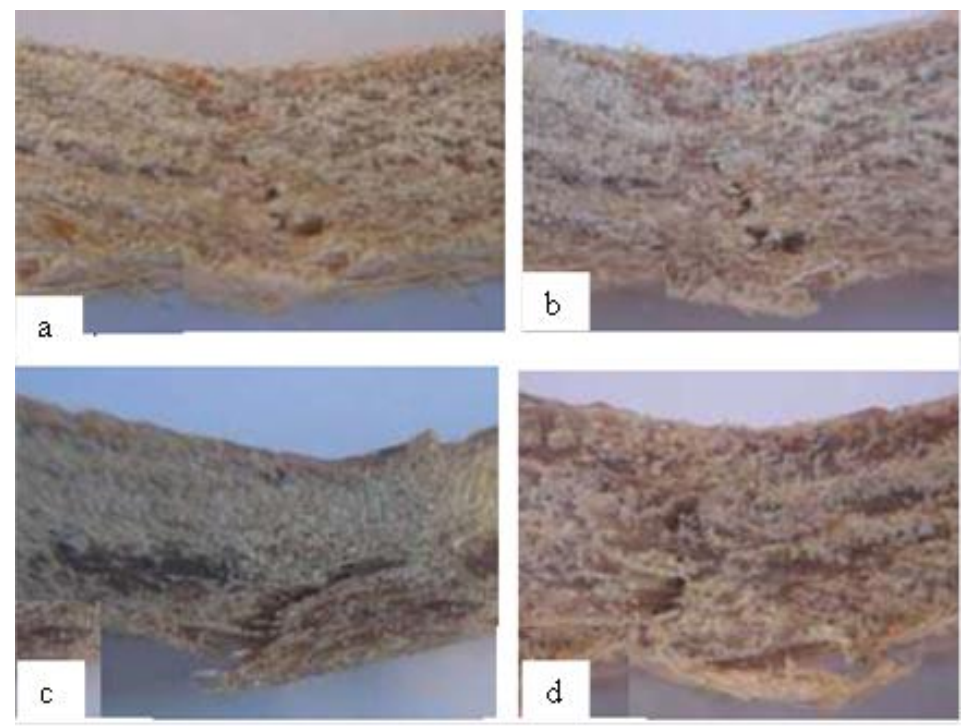

Figure 5 Macro Structure Failure of Speciment. a. 5 \% MASF, b. 10 \% MASF, c. 15 \% MASF, d. 20 \% MASF 


\section{Conclusion}

From the results of the Impact test, the greater the MASF volume fraction added, the toughness of the composite material will increase (more ductile), but this does not apply to a volume fraction ratio of more than $20 \%$ MASF, the impact toughness tends to decrease. Because the fibers and the Matrix are not able to bind properly. SEM observations, only at the $20 \%$ MASF volume fraction, the matrix and the fibers were well adhered. Damage to the surface of the matrix and its reinforcement (fiber), indicates that the bond strength between the matrix and the reinforcement is not properly bonded.

\section{Compliance with ethical standards}

\section{Acknowledgments}

The intellectual and moral contributions of Prof. DR. Ir. Rudy Soenoko, Msc.Eng., Prof. DR. Eng. Ir. IGN. Wardana, among others towards the success of this work are deeply appreciated.

\section{Disclosure of conflict of interest}

No conflict of interest.

\section{References}

[1] Annual Book of ASTM Standards, D790, Standard Test Method For Flexural Properties Of Unreinforced And Reinforced Plastics And Electrical Insulating Material, ASTM Standards and Literature References for Composite Materials, 2nd ed., 1997, pp.34-37, American Society for Testing and Material, Philadelphia.

[2] Braga RA. Rear Bumper Laminated In Jute Fiber With Polyester Resin, Int. Journal of Engineering Research and Applications (IJERA), 2014; Vol. 4, Issue 9, pp. 174-184.

[3] Hee-Soo Kim. Enhanced Interfacial Adhesion, Mechanical, and Thermal Properties of Natural Flourfilled Biodegradable Polymer Bio-composites, J Therm Anal Calorim. 2011; 104: 331-338.

[5] Thiruchitrambalam M. Improving Mechanical Properties of Banana/Kenap Polyester Hybrid Composites Using Sodium Laulryl Sulfate Treatment, Material Physics and Mechanics. 2009; 8: 165-173.

[4] Nopparut, Ajjima \& Amornsakchai, Taweechai,. Influence of pineapple leaf fiber and it's surface treatment on molecular orientation in, and mechanical properties of, injection molded nylon composites. Polymer Testing. 52. 141-149. 10.1016/j.polymertesting.2016: 04.012.

[5] L. Yan, N. Chouw, and X. Yuan, Improving the mechanical properties of natural fibre fabric reinforced epoxy composites by alkali treatment, Journal of Reinforced Plastics and Composites, 2012: vol. 31, no. 6, pp. $425-437$.

[6] Tumpal Ojahan R. The Effect of Recycled Polypropylene (RPP) Banana Stem Volume Fraction on Mechanical and Physical Properties. BKSTM. 2013.

[7] Q. Liu, T. Stuart, M. Hughes, H. S. S. Sharma, and G. Lyons, Structural biocomposites from flax-part II: the use of PEG and PVA as interfacial compatibilising agents, Composites Part A: Applied Science and Manufacturing, 2007; vol. 38, no. 5, pp. 1403-1413.

[8] Lokantara I Putu. The Effect of Fiber Length at Different Test Temperature on Tensile Strength of Coconut Filter Polyester Composites, Mechanical Engineering Scientific Journal. 2010; 4(2): 166-172.

[9] Bakri. Overview of Coconut Coir Fiber Application as Composite Material Strengthening, Mechanical Journal. 2011; 2(1), pp. 10-15.

[10] Maleque M, Yousif B, Sapuan S. Mechanical properties study of pseudo-stem banana fiber reinforced epoxy composite, Arabian Journal for Science and Engineering. 2007; 32.

[11] Prakasha, Kiran UM, Mahadev. Investigative Studies on the Mechanical Behaviour of Banana Fiber Sugarcane Bagasse Powder Reinforced Polymer Composites, IJSART. 2016; 2(6). 